\title{
The Role, Mechanism and Transcriptional Regulation of LAT in Herpes Simplex Virus Latency and Reactivation
}

\author{
Ying Zhang1,2*, Yingying Wang1,2*, Junting Cheng1,2, Wenqi Cai1,2, Ziwen Han ${ }^{1,2}$, Yang Zhou1,2, \\ Qi Huang1,2, Moyu Wang1,2, Xiaochun Peng ${ }^{3}$, Xianwang Wang ${ }^{4}$, Zhaowu Ma1,2, Ying Xiang1,2\#, \\ Hongwu Xin ${ }^{1,2 \#}$
}

\begin{abstract}
${ }^{1}$ Laboratory of Oncology, Center for Molecular Medicine, School of Basic Medicine, Health Science Center, Yangtze University, Jingzhou, China

${ }^{2}$ Department of Biochemistry and Molecular Biology, School of Basic Medicine, Health Science Center, Yangtze University, Jingzhou, China

${ }^{3}$ Department of Pathophysiology, School of Basic Medicine, Health Science Center, Yangtze University, Jingzhou, China ${ }^{4}$ Department of Laboratory Medicine, School of Basic Medicine, Health Science Center, Yangtze University, Jingzhou, China

Email: "xying316@163.com, "hongwu_xin@126.com
\end{abstract}

How to cite this paper: Zhang, Y., Wang, Y.Y., Cheng, J.T., Cai, W.Q., Han, Z.W., Zhou, Y., Huang, Q., Wang, M.Y., Peng, X.C., Wang, X.W., Ma, Z.W., Xiang, Y. and Xin, H.W. (2020) The Role, Mechanism and Transcriptional Regulation of LAT in Herpes Simplex Virus Latency and Reactivation. Yangtze Medicine, 4, 39-53. https://doi.org/10.4236/ym.2020.41004

Received: December 17, 2019

Accepted: March 27, 2020

Published: March 30, 2020

Copyright $\odot 2020$ by author(s) and Scientific Research Publishing Inc. This work is licensed under the Creative Commons Attribution-NonCommercial International License (CC BY-NC 4.0). http://creativecommons.org/licenses/by-nc/4.0/ (c) (i) \&) Open Access

\begin{abstract}
Herpes simplex virus (HSV) infection in the human body can be latent in neurons for long time and be reactivated leading to recurrence at high rate. Currently there is no effective clinical strategy for the prevention and treatment of the disease relapse. HSV LAT gene is expressed in large quantities and lytic genes are turned off leading to HSV latency. Disruption of the gene expression is thought to cause HSV reactivation and disease relapse. To reveal the essence of HSV latency and reactivation, we summarized and innovatively classified the role, mechanism and transcriptional regulation of LAT in HSV latency and reactivation. This review may have important implications for future studies on HSV latency and reactivation, HSV disease prevention and treatment, and safer and more effective oncolytic HSVs (oHSVs).
\end{abstract}

\section{Keywords}

Herpes Simplex Virus (HSV), Oncolytic Herpes Simplex Virus (oHSV), Latency-Associated Transcript (LAT), Reactivation, Immediate-Early Gene (IE Gene)

\section{Introduction}

Herpes simplex virus (HSV) can be latent in trigeminal neurons in the host for

${ }^{*}$ Authors contributed equally. 
several years or establishes a lifelong latent infection [1] [2] [3]. HSV causes a variety of human diseases [4], including infectious corneal blindness [5], gastrointestinal disorders, esophageal disorders and genital herpes infections during both primary and recurrent infections [6] [7] [8]. During primary infection, HSV-1 causes diseases that range from asymptomatic infections and cold sores, to blinding stromal keratitis and lethal encephalitis. Whereas HSV-2 infection usually leads to genital herpes [9] [10]. After a primary infection, HSV can be latent in the ganglia. Latent HSV can become reactivated causing disease relapse by evading host immunity, such as macrophages natural killer cells and interferon [11]. HSV can also spread between cells without reaching the extracellular environment. HSV is cleared by three types of immune responses in the host body: Specific cytotoxic T cells, specific delayed hypersensitivity, and antibodies. When the HSV specific antibodies reach the appropriate level, they can prevent HSV invasion of the nervous system. HSV latency makes it clinically impossible to treat HSV diseases.

It's known that latency associated transcript (LAT) is the only viral gene with high-level expression during HSV latency-reactivation cycle [12]. The LAT plays an important role in promoting latent infection by promoting cell survival, inhibiting apoptosis or other mechanisms of cell death [13] [14], repressing lytic gene expression [15] [16], and facilitating heterochromatin accumulation of the viral genome [17] [18]. It is controversial whether LAT can be successfully translated into proteins. One study showed that LAT gene did not encode any functional protein [19]. However, the LAT region contains numerous open reading frames (ORFs). Some researchers believed that LAT, or regions in the LAT gene, coded for proteins [20] [21] [22]. It was also suggested that the proteins encoded by HSV LAT in the ORFs were probably transient and difficult to detect. LAT-encoded proteins have not been experimentally detected [23]. At present, the hypothesis that LAT can encode proteins is still in the stage of experimental exploration, which needs further verification. It is of special significance to clarify the relevant mechanism of latent infection and recurrence of this virus to effectively prevent and treatment of HSV infection and recurrence [24].

In addition, tumors consist mainly of transformed cells, such as tumor stem cells [25] [26] [27] [28]. Recently, HSV has been successfully used to treat tumors as oncolytic HSV (oHSV) [29] [30] [31] [32]. oHSVs replicate preferentially in tumor cells but not in normal cells [33]. Research showed that the molecules, such as herpes virus entry mediator (HVEM) and three of its ligands (BTLA, CD160, and LIGHT), were up-regulated due to the presence of LAT in trigeminal ganglion (TG) of latently infected LTa -/- mice [34]. LTa induces apoptosis [35] while LAT has antiapoptotic function [36]. However, the mechanism of LAT against apoptosis is still not fully understood. LAT down-regulates the activation of apoptotic caspases 3,8 and 9 [19]. In vitro, the cleavage of caspase 8 and 9 was inhibited in wild type HSV infected nerve 2A cells, while LAT deletion mutant viruses did not [37], indicating that the function of LAT was achieved by inhibiting the activation of pro-apoptotic caspases. 
The presence of LAT is a marker of HSV latency and its expression is essential for the establishment, maintenance and reactivation of HSV latency in neurons [24] [38]. Thus, deletion of LAT can reduce latency and reactivation of HSV infection to construct safe oHSV [39]. Recent studies have shown that deletion of the LAT gene from the HSV genome can significantly improve the efficacy and safety of oHSV [40] [41].

This review highlighted the hypothesis, evidence and the mechanisms of LAT related HSV latent infection and recurrence, and the multiple functions of LAT were analyzed at the levels of transcription and translation. Our review of the latest research progress of LAT will provide new insights for the further understanding of HSV infection and therapy, and future construction of better oHSVs.

\section{LAT in HSV Latency}

\subsection{Current Theory of LAT Mediated HSV Latency}

HSV enters the cell through a fusion between the viral envelope and the cell membrane. Once inside the cytoplasm, the capsid is dissociated and transported to nuclear pores via tubule-related motional proteins, where the viral genome is released into the nucleus in a circular configuration [42]. It then begins to express immediate early (IE) genes (coding for regulatory proteins), early gene expression (especially proteins coding for DNA replication devices), and late gene expression after DNA synthesis begins [42]. It is not yet clear exactly how the HSV latent state is established and reactivated. Here we summarized several latency and reactivation mechanisms to provide new ideas for future research (Table 1).

Latency is a state of virus infection, in which through interaction with the host cell viruses limit their own gene expression, keep their genome into a silent state, but remain in the host neuron cell [43]. HSV particles are retrograde to the neuronal cell body, releasing viral DNA into the nucleus. When LAT is expressed the HSV genome binds to nucleosomes (specifically nucleosome histones $\mathrm{H} 3 \mathrm{~K} 27 \mathrm{me} 3$ and $\mathrm{H} 3 \mathrm{~K} 9 \mathrm{me} 3 / 2$ ) to form tight chromatin and silence the lytic genes, promoting HSV latency [18].

Under latent conditions, LAT and several miRNAs remain highly expressed, silencing the lytic gene expression, especially immediate early (IE) gene expression, to inhibit virus replication and promoting the survival of infected neurons [44] [45], thus effectively promoting the establishment of HSV latency [46]. Therefore, the viral genome is in a non-replicating state in sensory neurons [47]. During latency HSV is not detected at the original site of infection [48]. ICP0 protein can promote LAT transcription and silence viral lytic gene expression by histone modification and heterochromatin formation [49]. ICP0 may be a target for antiviral drugs against latent infection. HSV-1-KOS/M with basic LAT promoter or LAT gene $5^{\prime}$ end deletion became latent in about $30 \%$ of neurons [50]. HSV-1-KOS/M with LAT deletion became latent in about $10 \%$ of neurons. It has been suggested that the $2.3 \mathrm{~kb}$ region of LAT is the primary latency determinant. 
Table 1. HSV latency and reactivation mechanisms mediated by LAT.

\begin{tabular}{|c|c|c|c|}
\hline Latency mechanism & Latency establishment & Reactivation & HSV strain and ref. \\
\hline $\begin{array}{l}\text { Chromatin modification } \\
\text { leads to lytic gene } \\
\text { silencing and expression } \\
\text { of LATs and miRNA. }\end{array}$ & $\begin{array}{l}\text { HSV infection at the } \\
\text { distal axon, retrograde } \\
\text { to neuronal nucleus. }\end{array}$ & $\begin{array}{l}\text { LAT induces } \\
\text { efficient } \\
\text { reactivation. }\end{array}$ & $\begin{array}{c}\text { HSV-1-KOS/62/17/ } \\
\text { McKrae [44] }\end{array}$ \\
\hline $\begin{array}{l}\text { In sensory neurons, } \\
\text { HSV genome remains } \\
\text { nonreplicative and viral } \\
\text { genes are silenced } \\
\text { except LAT. }\end{array}$ & $\begin{array}{l}\text { LAT deletion analysis } \\
\text { indicated that LAT } \\
\text { enhances the } \\
\text { latency establishment. }\end{array}$ & $\begin{array}{l}\text { Fever, stress, } \\
\text { and UV } \\
\text { irradiation } \\
\text { or abrasion. }\end{array}$ & HSV-1-17/F [51] \\
\hline $\begin{array}{l}\text { LAT is able to play an } \\
\text { indispensable role in the } \\
\text { establishment of incubation } \\
\text { period via reducing } \\
\text { mRNA levels of IE gene. }\end{array}$ & $\begin{array}{l}\text { LAT inhibits viral } \\
\text { replication in } \\
\text { nerve cells }\end{array}$ & $\begin{array}{l}\text { LAT enables HSV } \\
\text { reactivation. }\end{array}$ & HSV-1-F/KOS [46] \\
\hline $\begin{array}{l}\text { HSV virions are } \\
\text { transported to the cell } \\
\text { body within the } \\
\text { TG to suppress } \\
\text { effectively lytic genes. }\end{array}$ & $\begin{array}{l}\text { When the virus cleavage } \\
\text { gene is suppressed, the } \\
\text { HSV genome enters a } \\
\text { nucleosomal associated } \\
\text { latent state without } \\
\text { DNA replication in } \\
\text { the sensory ganglia. }\end{array}$ & A stress stimulus. & HSV-1-17/KOS [48] \\
\hline $\begin{array}{l}\text { ICP0 promoted histones } \\
\text { and heterochromatin } \\
\text { modifications to silence } \\
\text { lytic gene expression. }\end{array}$ & $\begin{array}{l}\text { ICP0 promoted } \\
\text { the establishment } \\
\text { of latency. }\end{array}$ & $\begin{array}{l}\text { ICP0 accelerates } \\
\text { the expression } \\
\text { of LAT and lytic } \\
\text { genes in latent } \\
\text { infected ganglia. }\end{array}$ & HSV-1-KOS [49] \\
\hline
\end{tabular}

\subsection{Other Mechanisms Reported in LAT Mediated HSV Latency}

At present, the understanding of the process of latent establishment and maintenance of HSV is constantly updated. There are many latent hypotheses are put forward, here we summarize the LAT related latency hypotheses into the following four categories for subsequent experimental studies.

1) Repression of ICP0 by the antisense RNA of LAT. Garber [16] et al. found that the gene sequence of LAT overlapped the virus immediate-early gene (IE gene) ICP0 in the antisense direction. Therefore, the LAT with high expression formed a hybrid with the mRNA of ICP0 through the antisense mechanism, preventing its modification, transport and translation, and thus blocking the generation of ICP0 protein. Since ICP0 is essential for regulating HSV genome replication, inhibition of ICP0 expression shifts the virus from productive to latent infection.

2) The anti-apoptosis effect of $1.5 \mathrm{~kb}$ LAT. Perng et al. [52], found in an animal model of rabbit, the expression of the $1.5 \mathrm{~kb}$ LAT only of HSV mutant strains showed the same capacity of latency and reactivation to the wide type HSV. LAT played a role in the process of HSV latency and reactivation was the initial $1.5 \mathrm{~kb}$ LAT of primary transcript, and the $1.5 \mathrm{~kb}$ LAT gene sequence had no genetic overlap with the IE gene, which suggested that LAT played a role by 
other mechanisms, rather than by antisense mechanisms. Perng [36] et al. then showed that LAT has an anti-apoptotic effect by using in vitro experiments to construct plasmids expressing LAT that blocked the Fas antibody induced apoptosis.

3) Repression of ICP4 by the antisense RNA of LAT and anti-apoptosis miRNA-LAT. Chen et al. [53] found that the expression of LAT and ICP4 had a reverse relationship, and LAT down-regulated the expression of HSV lytic gene by inhibiting ICP4 through antisense, so as to promote the establishment and maintenance of HSV latent infection. LAT also has the function of anti-neuronal apoptosis. It encodes miRNA-LAT that mediated virus anti-apoptosis effect, thus preventing HSV from being cleared due to host apoptosis [54]. Carpenter et al. [55] also proved that the anti-apoptosis effect of LAT gene was conducive to the reactivation of latent virus.

4) The HSV miRNAs-ICP0/4-T cells. After entering the cytoplasm, HSV rapidly dissolves the capsid and then enters the nucleus via the nuclear pore. At this point, the virus begins to express IE genes, particularly those encoding the viral replication ICP0 and ICP4 [42]. Recently, it has been shown that miRNAs encoded by HSV-1 itself have regulatory capacities for viral genes and might control the virus latency state [56]. Two of these miRNAs were shown to reduce expression of ICP0 and ICP4 in vitro [57], leading to viral DNA replication suppression and HSV latency. In addition, the viral miRNAs targeted viral antigen (for example ICP4) expression reduction may cause HSV immune escape from infiltrating T cells, leading to HSV latency by a noncytolytic mechanism [58].

The understanding of HSV latency mechanism has been in dispute. Although many hypotheses have been put forward, none of them can fully explain HSV latency mechanism. Perhaps HSV latency is the result of multiple mechanisms and needs to be analyzed further.

\section{LAT in HSV Reactivation}

\subsection{Current Theory of LAT Mediated HSV Reactivation}

In natural HSV human infection, factors such as ultraviolet radiation, emotional stress, fever, tissue damage and immunosuppression can induce HSV reactivation. Experiments have showed that under certain conditions, such as fever, stress, and UV irradiation or abrasion, HSV-1 strain 17/F is reactivated [51]. Many inducing factors are related to the process of stress, so scholars have been looking for the link between stress and reactivation. Some believe that LAT has no direct role in virus reactivation [14], however, others suggest that LAT plays an irreplaceable role in activation [59]. Using LAT targeted ribozyme delivered to a HSV-1 infected eye of a rabbit, one study demonstrated that HSV-1 LAT promoted effective HSV reactivation from latency [9].

LAT may promote HSV activation by inhibiting apoptosis [19]. To some extent, the survival of neuronal cells can be achieved [60] [61]. One research found that the anti-apoptotic activity of LAT is sufficient to reactivate HSV, since re- 
placing LAT with any of the three tested anti-apoptotic genes reactivated HSV to wild type levels [62]. Furthermore, LAT may regulate reactivation by affecting the immune response [8]. Liu et al. [63] found that interdicting $\mathrm{CD}^{+} \mathrm{T}$ cell function through monoclonal antibody could increase the in vitro reactivation rate of HSV in mouse ganglion, indicating that LAT may promote HSV reactivation by controlling infiltrating $\mathrm{CD}^{+} \mathrm{T}$ cells in latent infected ganglia. How LAT regulates the $\mathrm{CD}^{+} \mathrm{T}$ cell infiltration remains unclear. Mice infected with LAT-deficient HSV-2 [64] showed decrease of spontaneous reactivation rate, which was not related to the increase of $\mathrm{CD}^{+} \mathrm{T}$ cells [65]. With similar latent viral load, the reactivation rate of LAT-deficient HSV-2 was lower than that of LAT restored HSV-2 [50]. Therefore, LAT may promote HSV reactivation through anti-apoptosis, $\mathrm{CD} 8^{+} \mathrm{T}$ cells, or other mechanisms.

\subsection{Other Mechanisms Reported in LAT Mediated HSV Reactivation}

HSV LAT may be reactivated under certain stimulus conditions. Here we summarize two other reactivation mechanisms.

1) LAT mRNA was translated to a protein that promotes reactivation of latent HSV. Under the reactivation condition (Table 1), the viral protein produced by HSV-LAT was significantly reduced, which induced the survival of neurons and produced an efficient reactivation of HSV-1 strain KOS/62/17/McKrae [44]. However, Thomas [21] et al. found that a $30 \mathrm{kDa}$ protein encoded by an open reading frame of $2 \mathrm{~kb}$ LAT exerted functions like ICP0 and promoted the growth of HSV. Their further study showed that the protein has a biological function and the regulation of the protein expression has important role in the latent infection of HSV [22].

2) The LATs may act at the initial stages of reactivation. One mechanism in neurons is to inhibit the reverse activation of the HSV-1 IE gene, which prevents the virus from successfully replicating in infected neurons with low replication rates [66] [67]. This hypothesis postulates that LATs are the only RNA expressed during the incubation period [68] [69] [70], which may allow the viral replication cycle to bypass this inhibition during the initial phase of activation. Meanwhile, LAT can also promote the expression of the IE genes at certain conditions, allowing reactivation of HSV-1 strain F/KOS [66]. Activation conditions under stress can lead to large amounts of transcription of the lytic genes, which can activate virus recurrence [48]. ICP0 has been shown to promote virus reactivation in HSV-1 strain KOS [71].

\section{Transcriptional Regulation of LAT}

The high level of LAT expression in host neurons enables HSV to effectively establish latency and reactivation. To understand how LAT may regulate the latency and reactivation of HSV, here we classified the research progresses of LAT transcriptional regulation into four molecular pathways (Figure 1). 


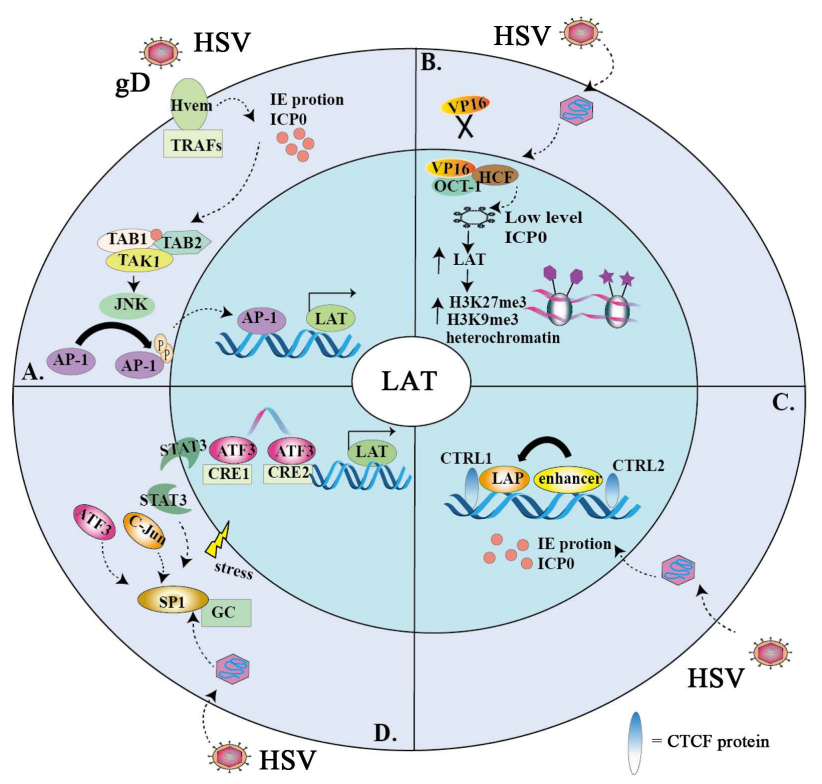

Figure 1. Four transcriptional regulation pathways of HSV LAT.

1) The ICP0-JNK-AP1-LAT pathway. HSV's gD envelope glycoprotein and its matching cell receptor, the HSV entry mediator (HVEM), a member of the TNFR superfamily whose cytoplasm area in combination with TRAFs [30]. The entry of HSV results in the synthesis of IE viral proteins involving ICP0. In turn, ICP0 catalyzes the K63-linked polyubiquitin chains with the help of Ubc13ev1A, which recognizes and interacts with the TAK1 [72]. Activated TAK1 then phosphorylates MKK6, leading to the activation of JNK kinase pathway [72]. JNK phosphorylated transcription factor AP-1. Phosphorylated AP-1 translocated into the nucleus to bind to the LAT transcription regulatory sequence, promotes transcription of LAT [49].

2) The VP16-LowICP0-LAT pathway. Multi-protein complex of VP16, Oct-1 and HCF to initiate IE transcription. However, as a capsule protein, VP16 cannot be successfully transported to ganglion nuclei with viral genomes because of certain physical losses. In absence of VP16, multi-protein complex (VP16, Oct-1 and HCF) cannot be formed, thus reducing IE gene transcription [73] [74]. Therefore, the IE gene encoding the ICP0 protein would be reduced. Low levels of ICP0 can promote both LAT and lytic gene expression in latently infected ganglia as well as total histone and heterochromatin loading on the latent HSV genome [49]. In contrast, in latently infected neuron nuclei the low levels of ICP0 expression can promote the expression of LAT and the accumulation of H3K27me3/H3K9me3 heterochromatin to silence lytic gene expression [18] [75].

3) The CTRL-CTCF-LAT pathway. When HSV enters the cytoplasm and the capsid breaks away, the viral genome begins to express IE genes. The IE genes encode the protein ICP0. It is important to note that the ICP0 encoding region is flanked by two CTCF binding motifs, the CTRL1 and CTRL2 [1]. Binding of CTRL sites, the insulators or enhancers, by the CTCF protein activates LAT 
promoter (LAP) transcription, making the virus latent. Recent works defining the CTCF-insulator's role in lytic gene transcription repression of $\beta$ and $\gamma$ herpes viruses further support the possibility that CTCF-insulators also regulate $\alpha$ herpes virus latency through lytic gene repression [1].

4) The Sp1-Stat3-ATF3-CRE-LAT pathway. Sp1 protein is endogenously abundant in SK-N-SH cells [76], can interact with a variety of GC rich promoter sequences, and can recruit STAT3, ATF3, and c-Jun complexes [76]. Normally, STAT3 is present in the cytoplasm of neurons, but in a certain state of stress, STAT3 quickly migrates to the nucleus [77], functions together with ATF3, repressing neuronal cell death [78]. It has been agreed that ATF3, as a regulator of stress response, is an immediate-early response gene that plays a key role in determining the fate of cells [79]. ATF3 can combine a cAMP response element (CRE) with the typical sequence of 5'-TGACGTCA-3' in the form of homodimers or heterodimers with other members of the ATF/CREB family [80]. HSV-1 DNA contains a total of eight CRE sites, but only two are in the promoter range, particularly in promoter 1 of LAT (LAP1) [81]. ATF3 binds to both CRE sites in LAP1, forms a homodimer, and fosters increased accumulation of LAT transcripts [80] [82], and plays a critical role in the maintenance of HSV-1 latency.

\section{Conclusion}

HSV causes a number of diseases that are incurable due to HSV latency and reactivation and so far, no effective vaccine has been developed. Notably, researchers are focused on understanding the mechanisms of HSV latency and reactivation, where LAT played an important role. We reviewed and innovatively classified the role, mechanisms and transcriptional regulation of LAT in HSV latency and reactivation. We hope this review will have important implications for future studies on HSV latency and reactivation, HSV disease control and engineering of safer and more effective oncolytic HSVs.

\section{Acknowledgements}

This work was partly supported by grants from the National Natural Science Foundation of China (81872412 to XHW, 81602303 to XY, 31700736 to WXW). We thank Hubei Province Natural Science Foundation of China (2016CFB180 to WXW), Foundation of Health and Family Planning Commission of Hubei Province (WJ2016-Y-02 To MZ, WJ2016Y07 To WXW), Hubei Province Scientific and Technological Research Project (Q20171306 to XWW), Jingzhou Science and Technology Development Planning Project (JZKJ15063 to WXW).

\section{Conflicts of Interest}

No conflict of interest exits in the submission of this manuscript, and manuscript is approved by all authors for publication. I would like to declare on behalf of my co-authors that the work described was original research that has not been published previously, and not under consideration for publication elsewhere, in whole or in part. 


\section{References}

[1] Washington, S.D., Edenfield, S.I., Lieux, C., et al. (2018) Depletion of the Insulator Protein CTCF Results in Herpes Simplex Virus 1 Reactivation in Vivo. Journal of Virology, 92, e00173-18. https://doi.org/10.1128/JVI.00173-18

[2] Lee, D.H. and Ghiasi, H. (2018) An M2 Rather than a $\mathrm{T}_{\mathrm{H}} 2$ Response Contributes to Better Protection against Latency Reactivation following Ocular Infection of Naive Mice with a Recombinant Herpes Simplex Virus 1 Expressing Murine Interleukin-4. Journal of Virology, 92, e0051-18. https://doi.org/10.1128/JVI.00051-18

[3] Ahmed, W. and Liu, Z.F. (2018) Long Non-Coding RNAs: Novel Players in Regulation of Immune Response upon Herpesvirus Infection. Frontiers in Immunology, 9, 761. https://doi.org/10.3389/fimmu.2018.00761

[4] Xu, X., Fan, S., Wang, X., et al. (2017) Analysis of the Protective Immunity Induced by Herpes Simplex Virus 1 Strain M3 with an Attenuated Phenotype Due to Mutations in the Viral ul7, ul41, and LAT Genes. Frontiers in Microbiology, 8, 1958. https://doi.org/10.3389/fmicb.2017.01958

[5] Alfonso-Dunn, R., Turner, A.W., Jean Beltran, P.M., et al. (2017) Transcriptional Elongation of HSV Immediate Early Genes by the Super Elongation Complex Drives Lytic Infection and Reactivation from Latency. Cell Host \& Microbe, 21, 507-517. https://doi.org/10.1016/j.chom.2017.03.007

[6] Gesser, R.M. and Koo, S.C. (1997) Latent Herpes Simplex Virus Type 1 Gene Expression in Ganglia Innervating the Human Gastrointestinal Tract. Journal of Virology, 71, 4103.

[7] Jones, C. (2003) Herpes Simplex Virus Type 1 and Bovine Herpesvirus 1 Latency. Clinical Microbiology Reviews, 16, 79-95.

https://doi.org/10.1128/CMR.16.1.79-95.2003

[8] Hoshino, Y., Pesnicak, L., Straus, S.E. and Cohen, J.I. (2009) Impairment in Reactivation of a Latency Associated Transcript (LAT)-Deficient HSV-2 Is Not Solely Dependent on the Latent Viral Load or the Number of CD8 ${ }^{+} \mathrm{T}$ Cells Infiltrating the Ganglia. Virology, 387, 193-199. https://doi.org/10.1016/j.virol.2009.02.004

[9] Watson, Z.L., Washington, S.D., Phelan, D.M., et al. (2018) In Vivo Knockdown of the Herpes Simplex Virus 1 Latency-Associated Transcript Reduces Reactivation from Latency. Journal of Virology, 92, e00812-18. https://doi.org/10.1128/JVI.00812-18

[10] Lv, X., Wang, H., Su, A., Xu, S. and Chu, Y. (2018) Herpes Simplex Virus Type 2 Infection Triggers AP-1 Transcription Activity through TLR4 Signaling in Genital Epithelial Cells. Virology Journal, 15, Article No. 173. https://doi.org/10.1186/s12985-018-1087-3

[11] Su, A.R., Qiu, M., Li, Y.L., et al. (2017) BX-795 Inhibits HSV-1 and HSV-2 Replication by Blocking the JNK/p38 Pathways without Interfering with PDK1 Activity in Host Cells. Acta Pharmacologica Sinica, 38, 402-414.

https://doi.org/10.1038/aps.2016.160

[12] Perng, G.C., Dunkel, E.C., Geary, P., et al. (1994) The Latency-Associated Transcript Gene of Herpes Simplex Virus Type 1 (HSV-1) Is Required for Efficient in Vivo Spontaneous Reactivation of HSV-1 from Latency. Journal of Virology, 68, 8045-8055.

[13] da Silva, L.F. and Jones, C. (2013) Small Non-Coding RNAs Encoded within the Herpes Simplex Virus Type 1 Latency Associated Transcript (LAT) Cooperate with the Retinoic Acid Inducible Gene I (RIG-I) to Induce Beta-Interferon Promoter Ac- 
tivity and Promote Cell Survival. Virus Research, 175, 101-109. https://doi.org/10.1016/j.virusres.2013.04.005

[14] Thompson, R.L. and Sawtell, N.M. (2001) Herpes Simplex Virus Type 1 Latency-Associated Transcript Gene Promotes Neuronal Survival. Journal of Virology, 75, 6660-6675. https://doi.org/10.1128/JVI.75.14.6660-6675.2001

[15] Chen, S.H., Kramer, M.F., Schaffer, P.A., et al. (1997) A Viral Function Represses Accumulation of Transcripts from Productive-Cycle Genes in Mouse Ganglia Latently Infected with Herpes Simplex Virus. Journal of Virology, 71, 5878-5884.

[16] Garber, D.A., Schaffer, P.A. and Knipe, D.M. (1997) A LAT-Associated Function Reduces Productive-Cycle Gene Expression during Acute Infection of Murine Sensory Neurons with Herpes Simplex Virus Type 1. Journal of Virology, 71, 5885-5893.

[17] Wang, Q.Y., Zhou, C., Johnson, K.E., et al. (2005) Herpesviral Latency-Associated Transcript Gene Promotes Assembly of Heterochromatin on Viral Lytic-Gene Promoters in Latent Infection. Proceedings of the National Academy of Sciences of the United States of America, 102, 16055-16059. https://doi.org/10.1073/pnas.0505850102

[18] Cliffe, A.R., Garber, D.A. and Knipe, D.M. (2009) Transcription of the Herpes Simplex Virus Latency-Associated Transcript Promotes the Formation of Facultative Heterochromatin on Lytic Promoters. Journal of Virology, 83, 8182. https://doi.org/10.1128/JVI.00712-09

[19] Tormanen, K., Allen, S., Mott, K.R., et al. (2019) The Latency-Associated Transcript Inhibits Apoptosis via Downregulation of Components of the Type I Interferon Pathway during Latent Herpes Simplex Virus 1 Ocular Infection. Journal of Virology, 93, e00103-19. https://doi.org/10.1128/JVI.00103-19

[20] Perng, G.C., Maguen, B., Jin, L., et al. (2002) A Novel Herpes Simplex Virus Type 1 Transcript (AL-RNA) Antisense to the 5' End of the Latency-Associated Transcript Produces a Protein in Infected Rabbits. Journal of Virology, 76, 8003-8010. https://doi.org/10.1128/JVI.76.16.8003-8010.2002

[21] Thomas, S.K., Gough, G., Latchman, D.S., et al. (1999) Herpes Simplex Virus Latency-Associated Transcript Encodes a Protein Which Greatly Enhances Virus Growth, Can Compensate for Deficiencies in Immediate-Early Gene Expression, and Is Likely to Function during Reactivation from Virus Latency. Journal of Virology, 73, 6618-6625.

[22] Thomas, S.K., Lilley, C.E., Latchman, D.S. and Coffin, R.S. (2002) A Protein Encoded by the Herpes Simplex Virus (HSV) Type 12 -Kilobase Latency-Associated Transcript Is Phosphorylated, Localized to the Nucleus, and Overcomes the Repression of Expression from Exogenous Promoters When Inserted into the Quiescent HSV Genome. Journal of Virology, 76, 4056-4067. https://doi.org/10.1128/JVI.76.8.4056-4067.2002

[23] Shen, W., Sa e Silva, M., Jaber, T., et al. (2009) Two Small RNAs Encoded within the First 1.5 Kilobases of the Herpes Simplex Virus Type 1 Latency-Associated Transcript Can Inhibit Productive Infection and Cooperate to Inhibit Apoptosis. Journal of Virology, 83, 9131-9139. https://doi.org/10.1128/JVI.00871-09

[24] Roizman, B. and Whitley, R.J. (2013) An Inquiry into the Molecular Basis of HSV Latency and Reactivation. Annual Review of Microbiology, 67, 355-374. https://doi.org/10.1146/annurev-micro-092412-155654

[25] Xin, H.W., Ambe, C.M., Miller, T.C., et al. (2016) Liver Label Retaining Cancer Cells Are Relatively Resistant to the Reported Anti-Cancer Stem Cell Drug Metformin. Journal of Cancer, 7, 1142-1151. https://doi.org/10.7150/jca.10047 
[26] Xin, H.W., Ambe, C.M., Ray, S., et al. (2013) Wnt and the Cancer Niche: Paracrine Interactions with Gastrointestinal Cancer Cells Undergoing Asymmetric Cell Division. Journal of Cancer, 4, 447-457. https://doi.org/10.7150/jca.6896

[27] Xin, H.W., Ambe, C.M., Hari, D.M., et al. (2013) Label-Retaining Liver Cancer Cells Are Relatively Resistant to Sorafenib. Gut, 62, 1777-1786.

[28] Xin, H.W., Hari, D.M., Mullinax, J.E., et al. (2012) Tumor-Initiating Label-Retaining Cancer Cells in Human Gastrointestinal Cancers Undergo Asymmetric Cell Division. Stem cells, 30, 591-598. https://doi.org/10.1002/stem.1061

[29] Wu, Z.J., Tang, F.R., Ma, Z.W., et al. (2018) Oncolytic Viruses for Tumor Precision Imaging and Radiotherapy. Human Gene Therapy, 29, 204-222.

https://doi.org/10.1089/hum.2017.189

[30] Liu, X.Q., Xin, H.Y., Lyu, Y.N., et al. (2018) Oncolytic Herpes Simplex Virus Tumor Targeting and Neutralization Escape by Engineering Viral Envelope Glycoproteins. Drug Delivery, 25, 1950-1962. https://doi.org/10.1080/10717544.2018.1534895

[31] Gayral, M., Lulka, H., Hanoun, N., et al. (2015) Targeted Oncolytic Herpes Simplex Virus Type 1 Eradicates Experimental Pancreatic Tumors. Human Gene Therapy, 26, 104-113. https://doi.org/10.1089/hum.2014.072

[32] Twumasi-Boateng, K., Pettigrew, J.L., Kwok, Y.Y.E., et al. (2018) Oncolytic Viruses as Engineering Platforms for Combination Immunotherapy. Nature Reviews Cancer, 18, 419-432. https://doi.org/10.1038/s41568-018-0009-4

[33] Muik, A., Stubbert, L.J., Jahedi, R.Z., et al. (2014) Re-Engineering Vesicular Stomatitis Virus to Abrogate Neurotoxicity, Circumvent Humoral Immunity, and Enhance Oncolytic Potency. Cancer Research, 74, 3567-3578. https://doi.org/10.1158/0008-5472.CAN-13-3306

[34] Wang, S., Hirose, S. and Ghiasi, H. (2019) The Absence of Lymphotoxin- $\alpha$, a Herpesvirus Entry Mediator (HVEM) Ligand, Affects Herpes Simplex Virus 1 Infection in Vivo Differently than the Absence of Other HVEM Cellular Ligands. Journal of Virology, 93, e00707-19. https://doi.org/10.1128/JVI.00707-19

[35] Etemadi, N., Holien, J.K., Chau, D., et al. (2013) Lymphotoxin Alpha Induces Apoptosis, Necroptosis and Inflammatory Signals with the Same Potency as Tumour Necrosis Factor. The FEBS Journal, 280, 5283-5297.

https://doi.org/10.1111/febs.12419

[36] Perng, G.C., Jones, C., Ciacci-Zanella, J., et al. (2000) Virus-Induced Neuronal Apoptosis Blocked by the Herpes Simplex Virus Latency-Associated Transcript. Science, 287, 1500-1503. https://doi.org/10.1126/science.287.5457.1500

[37] Henderson, G., Peng, W., Jin, L., et al. (2002) Regulation of Caspase 8- and Caspase 9-Induced Apoptosis by the Herpes Simplex Virus Type 1 Latency-Associated Transcript. Journal of Neurovirology, 8, 103-111. https://doi.org/10.1080/13550280290101085

[38] Nicoll, M.P., Proena, J.T. and Efstathiou, S. (2012) The Molecular Basis of Herpes Simplex Virus Latency. FEMS Microbiology Reviews, 36, 684-705. https://doi.org/10.1111/j.1574-6976.2011.00320.x

[39] Lee, J.S., Raja, P., Pan, D., et al. (2018) CCCTC-Binding Factor Acts as a Heterochromatin Barrier on Herpes Simplex Viral Latent Chromatin and Contributes to Poised Latent Infection. mBio, 9, e02372-02317. https://doi.org/10.1128/mBio.02372-17

[40] Samoto, K., Perng, G.-C., Ehtesham, M., et al. (2001) A Herpes Simplex Virus Type 1 Mutant Deleted for $\gamma 34.5$ and LAT Kills Glioma Cells in Vitro and Is Inhibited for in Vivo Reactivation. Cancer Gene Therapy, 8, 269-277. 
https://doi.org/10.1038/sj.cgt.7700306

[41] Eissa, I.R., Naoe, Y., Bustos-Villalobos, I., et al. (2017) Genomic Signature of the Natural Oncolytic Herpes Simplex Virus HF10 and Its Therapeutic Role in Preclinical and Clinical Trials. Frontiers in Oncology, 7, 149. https://doi.org/10.3389/fonc.2017.00149

[42] Aranda, A.M. and Epstein, A.L. (2015) Herpes Simplex Virus Type 1 Latency and Reactivation: An Update. Medecine Sciences, 31, 506-514. https://doi.org/10.1051/medsci/20153105012

[43] Toma, H.S., Murina, A.T., Areaux, R.G., et al. (2009) Ocular HSV-1 Latency, Reactivation and Recurrent Disease. Seminars in Ophthalmology, 23, 249-273. https://doi.org/10.1080/08820530802111085

[44] Cabrera, J.R., Charron, A.J. and Leib, D.A. (2018) Neuronal Subtype Determines Herpes Simplex Virus 1 Latency-Associated-Transcript Promoter Activity during Latency. Journal of Virology, 92, e00430-18. https://doi.org/10.1128/JVI.00430-18

[45] Cunningham, A.L., Diefenbach, R.J., Miranda-Saksena, M., et al. (2006) The Cycle of Human Herpes Simplex Virus Infection: Virus Transport and Immune Control. The Journal of Infectious Diseases, 194, S11-S18. https://doi.org/10.1086/505359

[46] Mador, N., Goldenberg, D., Cohen, O., et al. (1998) Herpes Simplex Virus Type 1 Latency-Associated Transcripts Suppress Viral Replication and Reduce Immediate-Early Gene mRNA Levels in a Neuronal Cell Line. Journal of Virology, 72, 5067.

[47] Wagner, E.K. and Bloom, D.C. (1997) Experimental Investigation of Herpes Simplex Virus Latency. Clinical Microbiology Reviews, 10, 419-443. https://doi.org/10.1128/CMR.10.3.419

[48] Bloom, D.C., Giordani, N.V. and Kwiatkowski, D.L. (2010) Epigenetic Regulation of Latent HSV-1 Gene Expression. Biochimica et Biophysica Acta, 1799, 246-256. https://doi.org/10.1016/j.bbagrm.2009.12.001

[49] Raja, P., Lee, J.S., Pan, D., et al. (2016) A Herpesviral Lytic Protein Regulates the Structure of Latent Viral Chromatin. mBio, 7, e00633-00616.

https://doi.org/10.1128/mBio.00633-16

[50] Thompson, R.L. and Sawtell, N.M. (1997) The Herpes Simplex Virus Type 1 Latency-Associated Transcript Gene Regulates the Establishment of Latency. Journal of Virology, 71, 5432-5440.

[51] Colgin, M.A., Smith, R.L. and Wilcox, C.L. (2001) Inducible Cyclic AMP Early Repressor Produces Reactivation of Latent Herpes Simplex Virus Type 1 in Neurons in Vitro. Journal of Virology, 75, 2912-2920. https://doi.org/10.1128/JVI.75.6.2912-2920.2001

[52] Perng, G.C., Ghiasi, H., Slanina, S.M., et al. (1996) The Spontaneous Reactivation Function of the Herpes Simplex Virus Type 1 LAT Gene Resides Completely within the First 1.5 Kilobases of the 8.3-Kilobase Primary Transcript. Journal of Virology, 70, 976-984.

[53] Chen, S.H., Lee, L.Y., Garber, D.A., et al. (2002) Neither LAT nor Open Reading Frame $P$ Mutations Increase Expression of Spliced or Intron-Containing ICP0 Transcripts in Mouse Ganglia Latently Infected with Herpes Simplex Virus. Journal of Virology, 76, 4764-4772. https://doi.org/10.1128/JVI.76.10.4764-4772.2002

[54] Gupta, A., Gartner, J.J., Sethupathy, P., et al. (2006) Anti-Apoptotic Function of a microRNA Encoded by the HSV-1 Latency-Associated Transcript. Nature, 442, 82-85. https://doi.org/10.1038/nature04836 
[55] Carpenter, D., Henderson, G., Hsiang, C., et al. (2008) Introducing Point Mutations into the ATGs of the Putative Open Reading Frames of the HSV-1 Gene Encoding the Latency Associated Transcript (LAT) Reduces Its Anti-Apoptosis Activity. Microbial Pathogenesis, 44, 98-102. https://doi.org/10.1016/j.micpath.2007.07.001

[56] Kathrin, H., Andreas, J., Klaus, D., et al. (2011) Expression of Herpes Simplex Virus 1-Encoded microRNAs in Human Trigeminal Ganglia and Their Relation to Local T-Cell Infiltrates. Journal of Virology, 85, 9680. https://doi.org/10.1128/JVI.00874-11

[57] Umbach, J.L., Kramer, M.F., Igor, J., et al. (2008) MicroRNAs Expressed by Herpes Simplex Virus 1 during Latent Infection Regulate Viral mRNAs. Nature, 454, 780-783. https://doi.org/10.1038/nature07103

[58] Knickelbein, J.E., Khanna, K.M., Yee, M.B., et al. (2008) Noncytotoxic Lytic Granule-Mediated $\mathrm{CD}^{+} \mathrm{T}$ Cell Inhibition of HSV-1 Reactivation from Neuronal Latency. Science, 322, 268-271. https://doi.org/10.1126/science.1164164

[59] Yoshikawa, T., Hill, J.M., Stanberry, L.R., Bourne, N., Kurawadwala, J.F. and Krause, P.R. (1996) The Characteristic Site-Specific Reactivation Phenotypes of HSV-1 and HSV-2 Depend upon the Latency-Associated Transcript Region. Journal of Experimental Medicine, 184, 659-664. https://doi.org/10.1084/jem.184.2.659

[60] Silva, L.F.D. and Jones, C. (2013) Small Non-Coding RNAs Encoded within the Herpes Simplex Virus Type 1 Latency Associated Transcript (LAT) Cooperate with the Retinoic Acid Inducible Gene I (RIG-I) to Induce Beta-Interferon Promoter Activity and Promote Cell Survival. Virus Research, 175, 101-109. https://doi.org/10.1016/j.virusres.2013.04.005

[61] Jiang, X., Alami Chentoufi, A., Hsiang, C., et al. (2011) The Herpes Simplex Virus Type 1 Latency-Associated Transcript Can Protect Neuron-Derived C1300 and Neuro2A Cells from Granzyme B-Induced Apoptosis and CD8 T-Cell Killing. Journal of Virology, 85, 2325-2332. https://doi.org/10.1128/JVI.01791-10

[62] Ling, J., Carpenter, D., Moerdyk-Schauwecker, M., et al. (2008) Cellular FLIP Can Substitute for the Herpes Simplex Virus Type 1 Latency-Associated Transcript Gene to Support a Wild-Type Virus Reactivation Phenotype in Mice. Journal of Neurovirology, 14, 389-400. https://doi.org/10.1080/13550280802216510

[63] Liu, T., Khanna, K.M., Chen, X., et al. (2000) CD8 ${ }^{+}$T Cells Can Block Herpes Simplex Virus Type 1 (HSV-1) Reactivation from Latency in Sensory Neurons. Journal of Experimental Medicine, 191, 1459-1466.

https://doi.org/10.1084/jem.191.9.1459

[64] Krause, P.R., et al. (1995) Expression of the Herpes Simplex Virus Type 2 Latency-Associated Transcript Enhances Spontaneous Reactivation of Genital Herpes in Latently Infected Guinea Pigs. Journal of Experimental Medicine, 181, 297-306. https://doi.org/10.1084/jem.181.1.297

[65] Wang, K., Pesnicak, L., Guancial, E., Krause, P.R. and Straus, S.E. (2001) The 2.2-Kilobase Latency-Associated Transcript of Herpes Simplex Virus Type 2 Does Not Modulate Viral Replication, Reactivation, or Establishment of Latency in Transgenic Mice. Journal of Virology, 75, 8166-8172. https://doi.org/10.1128/JVI.75.17.8166-8172.2001

[66] Lillycrop, K.A., Estridge, J.K. and Latchman, D.S. (1993) The Octamer Binding Protein Oct-2 Inhibits Transactivation of the Herpes Simplex Virus Immediate-Early Genes by the Virion Protein Vmw65. Virology, 196, 888-891. https://doi.org/10.1006/viro.1993.1552

[67] Kemp, L.M., Dent, C.L. and Latchman, D.S. (1990) Octamer Motif Mediates Tran- 
scriptional Repression of HSV Immediate-Early Genes and Octamer-Containing Cellular Promoters in Neuronal Cells. Neuron, 4, 215-222. https://doi.org/10.1016/0896-6273(90)90096-X

[68] Spivack, J.G. and Fraser, N.W. (1987) Detection of Herpes Simplex Virus Type 1 Transcripts during Latent Infection in Mice. Journal of Virology, 61, 3841-3847.

[69] Steiner, I., Spivack, J.G., O’Boyle, D.R., et al. (1988) Latent Herpes Simplex Virus Type 1 Transcription in Human Trigeminal Ganglia. Journal of Virology, 62, 3493-3496.

[70] Stevens, J.G., Wagner, E.K., Devi-Rao, G.B., et al. (1987) RNA Complementary to a Herpesvirus Alpha Gene mRNA Is Prominent in Latently Infected Neurons. Science, 235, 1056-1059. https://doi.org/10.1126/science.2434993

[71] Halford, W.P. and Schaffer, P.A. (2001) ICP0 Is Required for Efficient Reactivation of Herpes Simplex Virus Type 1 from Neuronal Latency. Journal of Virology, 75, 3240-3249. https://doi.org/10.1128/JVI.75.7.3240-3249.2001

[72] Diao, L., Zhang, B., Xuan, C., et al. (2005) Activation of c-Jun N-Terminal Kinase (JNK) Pathway by HSV-1 Immediate Early Protein ICP0. Experimental Cell Research, 308, 196-210. https://doi.org/10.1016/j.yexcr.2005.04.016

[73] Wali, H., Lorentzen, E.U., Eing, B.R., et al. (2012) Entry of Herpes Simplex Virus Type 1 (HSV-1) into the Distal Axons of Trigeminal Neurons Favors the Onset of Nonproductive, Silent Infection. PLoS Pathogens, 8, e1002679. https://doi.org/10.1371/journal.ppat.1002679

[74] Roizman, B. and Sears, A.E. (1987) An Inquiry into the Mechanisms of Herpes Simplex Virus Latency. Annual Review of Microbiology, 41, 543-571.

https://doi.org/10.1146/annurev.mi.41.100187.002551

[75] Cliffe, A.R., Coen, D.M. and Knipe, D.M. (2013) Kinetics of Facultative Heterochromatin and Polycomb Group Protein Association with the Herpes Simplex Viral Genome during Establishment of Latent Infection. mBio, 4, 169-172. https://doi.org/10.1128/mBio.00590-12

[76] Sumiko, K.S., Ryuichi, K., Tokiko, O., et al. (2008) Neuronal Injury-Inducible Gene Is Synergistically Regulated by ATF3, c-Jun, and STAT3 through the Interaction with Sp1 in Damaged Neurons. Journal of Biological Chemistry, 283, 6988-6996. https://doi.org/10.1074/jbc.M707514200

[77] Dziennis, S. and Alkayed, N.J. (2008) Role of Signal Transducer and Activator of Transcription 3 in Neuronal Survival and Regeneration. Reviews in the Neurosciences, 19, 341-362. https://doi.org/10.1515/REVNEURO.2008.19.4-5.341

[78] Hunt, D., Raivich, G. and Anderson, P.N. (2012) Activating Transcription Factor 3 and the Nervous System. Frontiers in Molecular Neuroscience, 5, 7. https://doi.org/10.3389/fnmol.2012.00007

[79] Abe, T., Oue, N., Yasui, W. and Ryoji, M. (2003) Rapid and Preferential Induction of ATF3 Transcription in Response to Low Doses of UVA Light. Biochemical \& Biophysical Research Communications, 310, 1168-1174.

https://doi.org/10.1016/j.bbrc.2003.09.143

[80] Shu, M., Du, T., Zhou, G. and Roizman, B. (2015) Role of Activating Transcription Factor 3 in the Synthesis of Latency-Associated Transcript and Maintenance of Herpes Simplex Virus 1 in Latent State in Ganglia. Proceedings of the National Academy of Sciences of the United States of America, 112, E5420-E5426.

https://doi.org/10.1073/pnas.1515369112

[81] Ackland-Berglund, C.E., Davido, D.J. and Leib, D.A. (1995) The Roles of the 
cAMP-Response Element and TATA Box in Expression of the Herpes Simplex Virus Type 1 Latency-Associated Transcripts. Virology, 210, 141-151.

https://doi.org/10.1006/viro.1995.1325

[82] Millhouse, S., Kenny, J.J., Quinn, P.G., Lee, V. and Wigdahl, B. (1998) ATF/CREB Elements in the Herpes Simplex Virus Type 1 Latency-Associated Transcript Promoter Interact with Members of the ATF/CREB and AP-1 Transcription Factor Families. Journal of Biomedical Science, 5, 451-464.

https://doi.org/10.1007/BF02255935 